\title{
1,3,5-Trimethylpyrazolium chloride based ionogel as an efficient and reusable heterogeneous catalyst for the synthesis of benzimidazoles
}

\author{
PANKAJ SHARMA and MONIKA GUPTA* \\ Department of Chemistry, University of Jammu, Jammu 180 006, India \\ e-mail: monika.gupta77@ rediffmail.com
}

MS received 7 August 2015; revised 14 September 2015; accepted 8 October 2015

\begin{abstract}
A new approach for the synthesis of benzimidazoles using ionogel under solvent-free conditions is reported. Catalytic activity of ionogel was compared with silica coated with ionic liquid (silica-IL) and it was found that ionogel is highly active compared to silica-IL for the synthesis of benzimidazoles. Moreover, ionogel was recyclable for the synthesis of benzimidazoles.
\end{abstract}

Keywords. Ionogel; catalysis; ionic liquid; silica; benzimidazoles.

\section{Introduction}

It is well known that ionic liquids are playing an important role in synthetic chemistry and scientific interest in these liquids continues to grow exponentially. However, sometimes ionic liquids can cause problems in product separation and recovery of ILs, especially when the product is polar or somewhat soluble in water. Also, from the environment and economic point of view, heterogenization of homogeneous catalytic reactions has attracted much attention. ${ }^{1}$ Heterogenization of ionic liquids is an area of current research, which enables easy recovery and reuse of expensive catalysts.

Structures containing benzimidazole moiety are well known to have a wide range of biological applications. The properties of benzimidazole and its analogs have been studied since over hundred years. However, the main reason for greater interest of researchers towards benzimidazole derivatives is due to the fact that 5,6dimethyl-1-( $\alpha$-dribofuranosyl) benzimidazole is a basic part of the structure of vitamine $\mathrm{B}_{12}{ }^{2}$ Moreover, benzimidazole is also a structural unit of naturally occurring nucleotide due to which it easily interacts with biopolymers of living system. Due to this character, benzimidazoles are regarded as a promising class of bioactive heterocyclic compounds that exhibit a range of biological activities such as antihelminthic, ${ }^{3}$ antifungal, ${ }^{4}$ antimicrobial, ${ }^{5-7}$ antiviral ${ }^{8}$ and antineoplastic agents. ${ }^{9}$

No doubt, there are various synthetic approaches for the synthesis of benzimidazoles. ${ }^{10-15}$ Some of them include green procedures but some methods have certain drawbacks such as harsh reaction conditions, use

\footnotetext{
*For correspondence
}

of acids, long reaction times, difficult work-up or may be less substrate versatility. Still, there remains a demand to synthesize compounds via better methodology. Herein, we describe a study on the catalytic activity of ionogel prepared from tetrethylorthosilicate (TEOS) and 1,3,5-trimethylpyrazolium chloride through sol-gel process and comparison with silica coated with 1,3,5trimethylpyrazolium chloride for the synthesis of benzimidazoles. Our method involves simple work-up procedure, solvent-free conditions, less reaction time, tolerance to various functionalities and excellent yields,.

In our previous study, the ionogel was shown to be highly active for the synthesis of benzothiazoles. ${ }^{16}$ Earlier also, we reported the modification of catalyst with ionic liquid to improve the catalytic behavior of the catalyst for one-pot synthesis of 1,4-dihydropyridines. ${ }^{17}$

\section{Experimental}

\subsection{Materials and instrumentation}

Silica gel was purchased from ACROS Organics and other used chemicals were purchased from Sigma Aldrich or Merck chemical companies and were used without further purification. IR spectra of the catalyst and the synthesized compounds were recorded in the range of $4000-300 \mathrm{~cm}^{-1}$ on a Shimadzu Prestige-21 spectrophotometer. TGA of the catalyst was obtained on a Linesis Thermal Analyser with heating of $10^{\circ} \mathrm{C}$ per minute. SEM was recorded on a SEM JS-7600F and TEM was recorded on CM200 PHILIPS transmission electron microscope. ${ }^{1} \mathrm{H}$ NMR and ${ }^{13} \mathrm{C}$ NMR of the compounds were obtained on a Bruker Avance III 


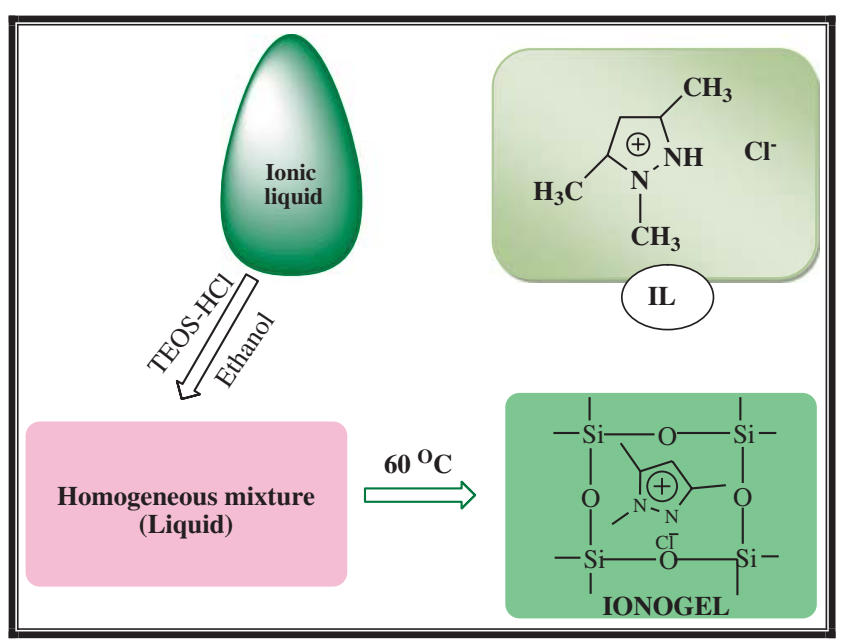

Scheme 1. General scheme for the preparation of ionogel.

(400 MHz) spectrometer. Mass spectra of the products were obtained on a Bruker Daltonics Esquire 3000 spectrometer.

The preparation and characterization of ionogel has already been described. ${ }^{16}$ The ionogel was synthesized from tetraethylorthosilicate and 1,3,5-trimethylpyrazolium through sol-gel process (scheme 1). The characterization of ionogel was done by SEM, TEM, FTIR and TGA. The SEM micrographs of the catalyst revealed the fine nature of ionogel, whereas TEM images revealed the formation of ionogel in the form of nanorods (figure 1). TGA graph indicated thermal stability of the ionogel and confirmed its ability to carry out reactions at $80^{\circ} \mathrm{C}$.

\subsection{General procedure for the synthesis of benzimidazoles using ionogel}

A mixture of aldehyde ( $2 \mathrm{mmol}), o$-phenylenediamine $(2 \mathrm{mmol})$ and ionogel $(0.1 \mathrm{~g})$ were taken in a round bottomed flask $(100 \mathrm{~mL})$ and stirred at $80^{\circ} \mathrm{C}$ on magnetic

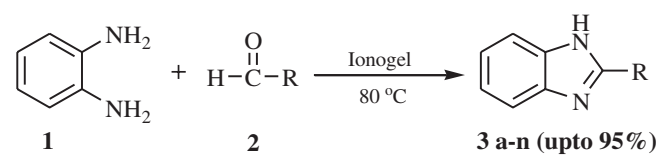

Scheme 2. Ionogel catalyzed synthesis of benzimidazoles.

stirrer under solvent-free conditions. After completion of reaction (monitored through TLC), the reaction mixture was treated with ethylacetate and then filtered at pump under reduce pressure. The filtrate obtained was concentrated and kept at room-temperature until solid product was formed in crystalline form which was then slightly washed with pet ether and ethylacetate in the ratio of 10:1 to obtain the product in pure form.

\section{Results and Discussion}

\subsection{Catalyst testing and optimization of reaction conditions}

In order to compare the activities of both synthesized catalysts, viz. silica supported ionic liquid catalyst (silica-IL) and ionogel, $m$-nitrobenzaldehyde and $o$-pheneylenediamine were chosen as test substrates for synthesizing 2-substituted benzimidazoles (scheme 2). The reaction was carried out at $80^{\circ} \mathrm{C}$ under solvent-free conditions and it was found that for the synthesis of 2substituted benzimidazoles, ionogel gave best results as compared to silica supported ionic liquid (table 1). The ionogel is basically three dimensional network of solid material encapsulating ionic liquid completely which may be the reason for high yield associated with ionogel compared to silica-IL.

In order to optimize the temperature for synthesis of benzimidazole, a test reaction was carried out at 40,60 , 80 and $100^{\circ} \mathrm{C}$ (table 1), it was found that the reactions carried out at $40^{\circ} \mathrm{C}$ and $60^{\circ} \mathrm{C}$ were very slow, but reaction at $80^{\circ} \mathrm{C}$ was clean and excellent yield of product
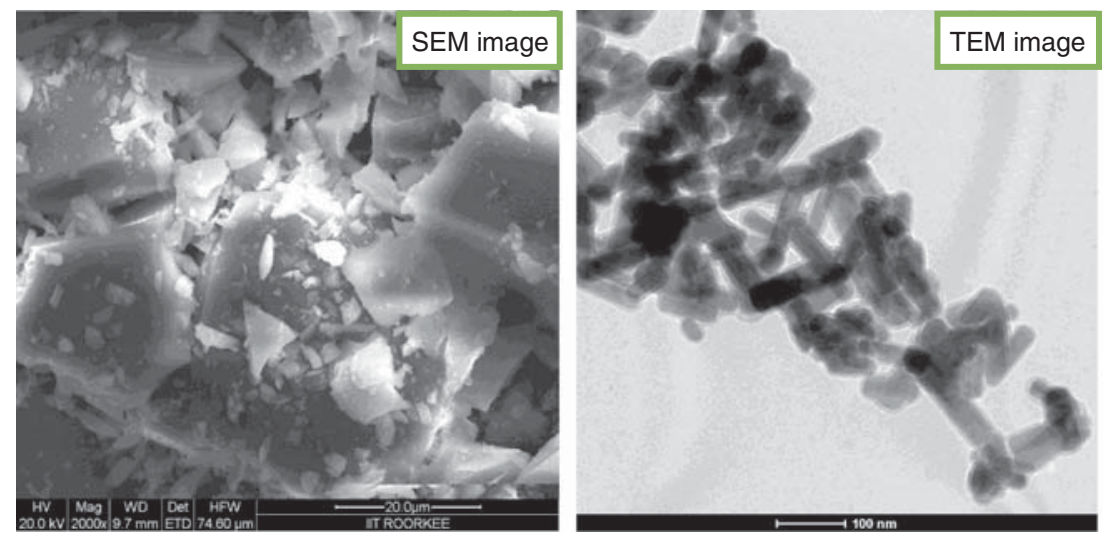

Figure 1. SEM and TEM images of the ionogel. 
Table 1. Effect of catalyst and temperature in the synthesis of benzimidazoles ${ }^{\mathrm{a}}$ under solvent-free conditions.

Entry Catalyst Temperature $\left({ }^{\circ} \mathrm{C}\right)$ Time (min.) Yield ${ }^{\mathrm{b}}(\%)$

\begin{tabular}{lcccc}
\hline 1 & Silica-IL & 80 & 20 & 50 \\
2 & Ionogel & 80 & 20 & 95 \\
3 & Ionogel & r.t. & 20 & trace \\
4 & Ionogel & 40 & 20 & 55 \\
5 & Ionogel & 60 & 20 & 70 \\
6 & Ionogel & 100 & 20 & 95 \\
\hline
\end{tabular}

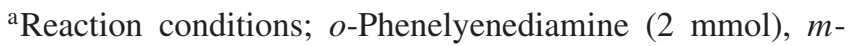
nitrobenzaldehyde ( $2 \mathrm{mmol})$, catalyst $(0.1 \mathrm{~g})$.

${ }^{\mathrm{b}}$ Isolated yield.

Table 2. Effect of solvents studied in the synthesis of benzimidazoles. ${ }^{\mathrm{a}}$

\begin{tabular}{lcccc}
\hline Entry & Solvent & Conditions & Time (min.) & Yield $^{\mathrm{b}}(\%)$ \\
\hline 1 & $\mathrm{CH}_{2} \mathrm{Cl}_{2}$ & Reflux & 40 & 30 \\
2 & $\mathrm{CH}_{3} \mathrm{OH}$ & Reflux & 20 & 50 \\
3 & $\mathrm{C}_{2} \mathrm{H}_{5} \mathrm{OH}$ & Reflux & 20 & 65 \\
4 & $\mathrm{H}_{2} \mathrm{O}$ & $80^{\circ} \mathrm{C}$ & 20 & 50 \\
5 & $\mathrm{CH}_{3} \mathrm{CN}$ & $80^{\circ} \mathrm{C}$ & 20 & 70 \\
6 & $\mathrm{No}-$ solvent & $80^{\circ} \mathrm{C}$ & 20 & 95 \\
\hline
\end{tabular}

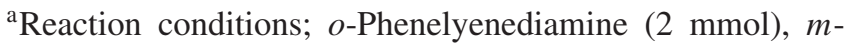
nitrobenzaldehyde ( $2 \mathrm{mmol})$, ionogel $(0.1 \mathrm{~g})$.

${ }^{\mathrm{b}}$ Isolated yield.

was obtained. At $100^{\circ} \mathrm{C}$, the reaction was not clean, may be due to multiple product formation, and also no significant increase in yield was observed above $80^{\circ} \mathrm{C}$. So, $80^{\circ} \mathrm{C}$ was chosen to be the best temperature for

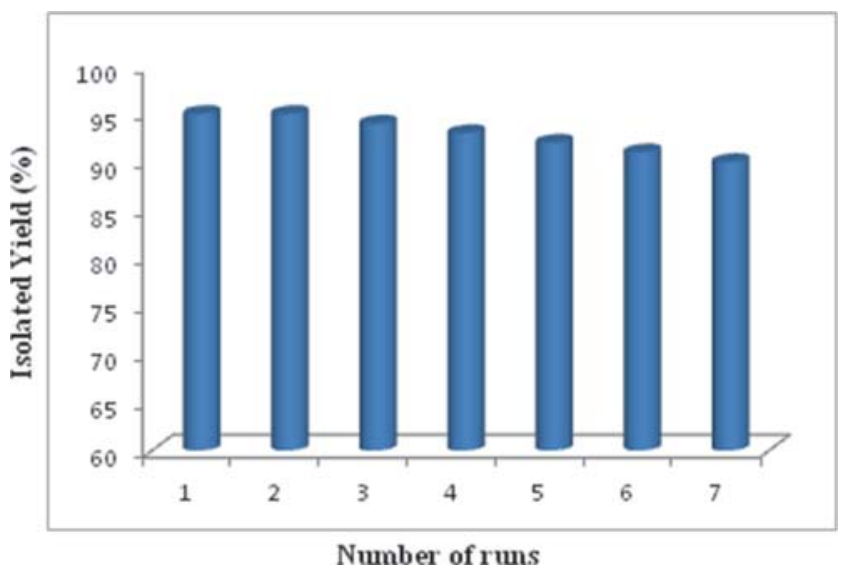

Figure 2. Recyclability graph of the ionogel in the synthesis of benzimidazole (3d, table 3 ).

synthesis of benzimidazoles. Solvent effect was also studied in the synthesis of benzimidazoles and among various tried solvents, solvent-less condition gave significant results (table 2).

To study the generality of this method, a variety of substrates were tried (table 3 ) for the synthesis of benzimidazoles and it was observed that aromatic, aliphatic and heterocyclic aldehydes all yielded good yield of products. Moreover, the catalyst worked very well with various functional groups including electron-releasing and electron-withdrawing groups with excellent yields.

\subsection{Recyclability of the Ionogel}

The important feature of ionogel was that it was reusable for several runs with very little loss in activity. To test

Table 3. Physical data of the synthesized benzimidazoles ${ }^{\mathrm{a}}$ catalyzed by ionogel.

\begin{tabular}{lccccc}
\hline Entry & Product & $\mathrm{R}$ & Time (min.) & Yield ${ }^{\mathrm{b}}(\%)$ & M.p./Lit. $\left({ }^{\circ} \mathrm{C}\right)$ \\
\hline 1 & $3 \mathrm{a}$ & $\mathrm{H}$ & 25 & 90 & $171-172 / 172-173^{18}$ \\
2 & $3 \mathrm{~b}$ & $\mathrm{CH}_{3}$ & 30 & 88 & $175-177 / 177-178^{19}$ \\
3 & $3 \mathrm{c}$ & $\mathrm{C}_{6} \mathrm{H}_{5}$ & 15 & 92 & $301-303 / 301-303^{20}$ \\
4 & $3 \mathrm{~d}$ & $3-\mathrm{NO}_{2} \mathrm{C}_{6} \mathrm{H}_{4}$ & 20 & 95 & $187-188 / 185-187^{21}$ \\
5 & $3 \mathrm{e}$ & $4-\mathrm{NO}_{2} \mathrm{C}_{6} \mathrm{H}_{4}$ & 10 & 94 & $324-326 / 326-327^{20}$ \\
6 & $3 \mathrm{f}$ & $2-\mathrm{NO}_{2} \mathrm{C}_{6} \mathrm{H}_{4}$ & 15 & 92 & $261-263 / 261-263^{22}$ \\
7 & $3 \mathrm{~g}$ & $4-\mathrm{ClC}_{6} \mathrm{H}_{4}$ & 20 & 90 & $291-292 / 290-292^{20}$ \\
8 & $3 \mathrm{~h}$ & $4-\mathrm{OHC}_{6} \mathrm{H}_{4}$ & 15 & 91 & $270-272 / 272-274^{23}$ \\
9 & $3 \mathrm{i}$ & $4-\mathrm{FC}_{6} \mathrm{H}_{4}$ & 25 & 90 & $250-252 / 250-252^{24}$ \\
10 & $3 \mathrm{j}$ & $4-\mathrm{BrC}_{6} \mathrm{H}_{4}$ & 10 & 94 & $296-297 / 297-298^{25}$ \\
11 & $3 \mathrm{k}$ & $4-\mathrm{MeC}_{6} \mathrm{H}_{4}$ & 15 & 90 & $264-266 / 263-265^{20}$ \\
12 & $3 \mathrm{l}$ & $4-\mathrm{MeOC}_{6} \mathrm{H}_{4}$ & 10 & 90 & $234-235 / 234-235^{20}$ \\
13 & $3 \mathrm{~m}$ & $4-\mathrm{OH}-3-\mathrm{MeOC}_{6} \mathrm{H}_{3}$ & 15 & 93 & $218-220 / 220^{26}$ \\
14 & $3 \mathrm{n}$ & $2-\mathrm{furyl}_{2}$ & 15 & 92 & $230-232 / 234-235^{27}$ \\
\hline
\end{tabular}

${ }^{a}$ Optimized reaction Conditions; $o$-Phenelyenediamine $(2 \mathrm{mmol})$, aldehyde $(2 \mathrm{mmol})$, ionogel $(0.1 \mathrm{~g})$, stirred at $80^{\circ} \mathrm{C}$ under solvent-free conditions.

${ }^{\mathrm{b}}$ Isolated yield. 


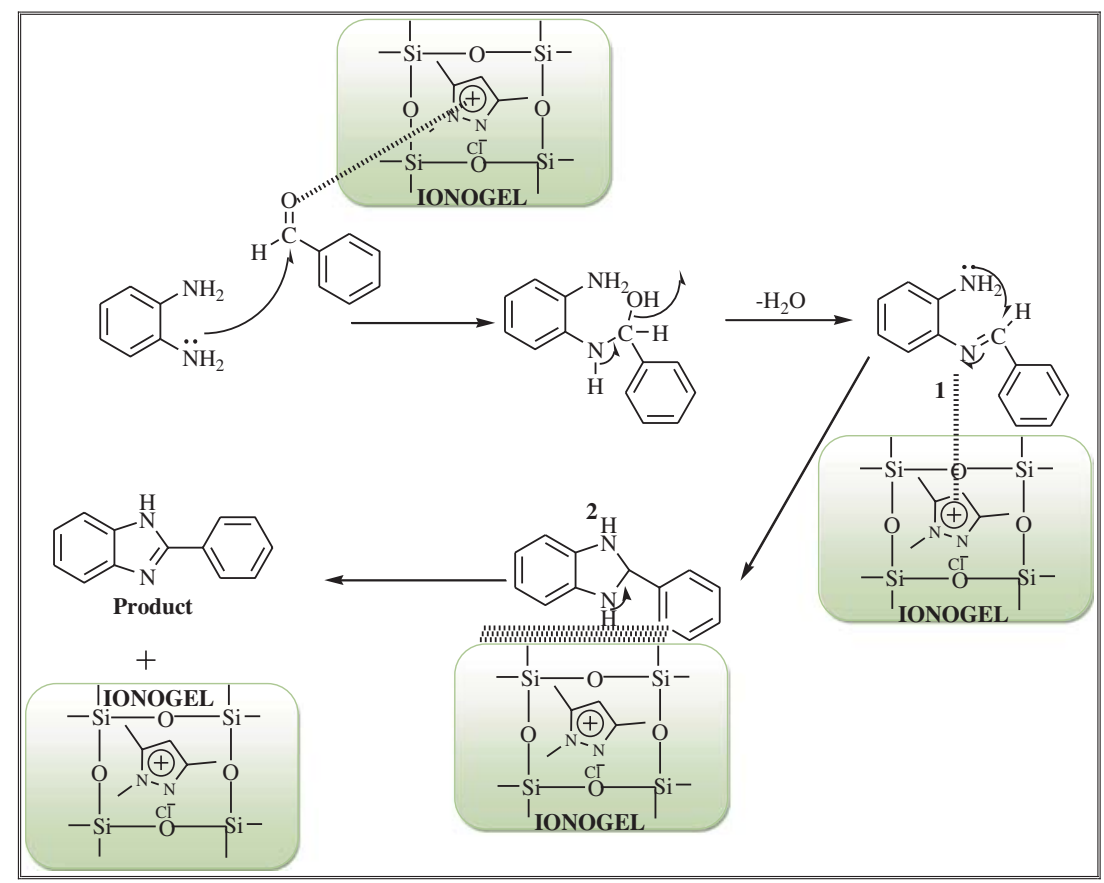

Figure 3. Proposed mechanism for the synthesis of benzimidazoles.

the recyclability of ionogel for the synthesis of benzimidazoles, a series of seven consecutive runs in the case of $m$-nitrobenzaldehyde (entry 4 , table 3 ) were carried out and the results are represented in figure 2 . These results demonstrated that ionogel is recyclable upto seven consecutive runs without significant loss of activity. The very little loss in activity may be attributed to reduction of some active sites of ionogel after each use.

\subsection{Proposed mechanism for the synthesis of benzimidazoles}

Ionogel as a heterogeneous catalyst provides active sites and large surface area for the reaction. Moreover, the presence of ionic liquid has a strong influence on the structural and textural properties of the catalyst. In the proposed mechanism (figure 3), ionogel provides surface area to both the reactants and facilitates the nucleophilic attack of $o$-phenlyenediamine on the carbonyl centre of aldehyde resulting in the formation of intermediate 1 which gets converted into the product by the loss of a $\mathrm{H}_{2}$.

\section{Conclusions}

In conclusion, we have developed a new kind of an efficient and selective procedure for the synthesis of benzimidazoles from $o$-phenylenediamine with aliphatic/ heterocyclic/aromatic aldehydes catalyzed by ionogel under solvent free conditions. 1,3,5-Trimethylpyra- zolium chloride based ionogel is a new and attractive solid support which can contribute to the development of catalytic processes and minimal environmental problems (reusable catalyst, non-toxicity of the catalyst, reduced amount of solvent, etc.). The recyclability of the catalyst makes the process greener and cost-effective.

\section{Supplementary Information}

Supplementary file contains details on preparation of the ionic liquid and its characterization, preparation of the ionogel and silica-supported catalyst, characterization of the ionogel including SEM, TEM, FTIR and TGA. It also contains spectral data of the synthesized compounds.

Supplementary Information is available at www.ias. ac.in/chemsci.

\section{Acknowledgements}

We are sincerely thankful to the Director, IIIM Jammu and SAIF Chandigarh for facilities for spectra; Head, Central Research facility section, IIT Roorkee for SEM and TEM. We also thank the Department of Chemistry, University of Jammu, for NMR, FTIR and TGA analysis. 


\section{References}

1. Desikan S and Doraiswamy L K 1995 Ind. Eng. Chem. Res. 34 3524; (b) McMorn P and Hutchings G J 2004 Chem. Soc. Rev. 33108

2. Spasov A A and Yozhitsa I N 1999 J. Pharm. Chem. 33 232

3. Mavrova A T S, Anichina K K and Vuchev D I 2005 Bioorg. Med. Chem. 135550

4. Goker H, Kus C and Boykin D W 2002 Bioorg. Med. Chem. 102589

5. Goker H, Kus C and Boykin D W 2005 Eur. J. Med. Chem. 401062

6. Andrzejewska M and Yepez M L 2002 Eur. J. Med. Chem. 37973

7. Ozden S, Atabey D and Goker H 2005 Bioorg. Med. Chem. 131587

8. Ramla M M and Omar M A 2006 Bioorg. Med. Chem. 147372

9. Boiani M and Gonzalez M 2005 Mini Rev. Med. Chem. 5409

10. Niknam K and Raviz A F 2007 J. Iran Chem. Soc. 4438

11. Bhatt A K, Karadia H G, Shah P R, Parmar M P and Patel H D 2004 Ind. J. Heterocycl. Chem. 13281

12. Kim Y, Kumar M R, Park N, Heo Y and Lee S $2011 \mathrm{~J}$. Org. Chem. 769577

13. Jacob R G, Dutra L G, Radatz C S, Mendes S R, Perin G and Lenardao E J 2009 Tetrahedron Lett. 50 1495
14. Oda S, Shimizu H, Aoyama Y, Ueki T, Shimizu S, Osato H and Takeuchi Y 2012 Org. Process Res. Dev. 1696

15. Prabhakar V, Babu K S, Ravindranath L K and Latha J 2015 World J. Pharmacy Pharma. Sci. 4553

16. Sharma P, Gupta M, Kant R and Gupta V K 2015 New J. Chem. 395116

17. Sharma P and Gupta M 2015 Green Chem. 171100

18. Valdez J, Cedillo R, Campos A H, Yepez L, Luis F H, Vazquez G N, Tapia A, Cortes R, Hernandez M and Castillo R 2002 Bioorg. Med. Chem. Lett. 122221

19. Hein D W, Alhein R J and Leavitt J J 1957 J. Am. Chem. Soc. 79427

20. Devalla V R and Ethirajulu K 1995 J. Chem. Soc. Perkin Trans. 21497

21. Eshghi H, Rahimizadeh M, Sedaghat P and Shiri A 2012 Bull. Korean Chem. Soc. 33515

22. Gadekar S L, Arbad R B and Lande K M 2010 Chin. Chem. Lett. 2191053

23. Latif N, Mishriky N, Assad F M and Meguid S B 1982 Indian J. Chem. 21B 872

24. Bougrin K, Loupy A and Soufiaoui M 1998 Tetrahedron 548055

25. Mahdavinia H G, Amani A M, Rostamizadeh S and Sepehrian H 2012 Heterocycl. Commun. 1833

26. Navarrete V G, Moreno D H, Estrada S S, Torres P M, Leon R I, Tlahuext H, Munoz M O and Torres G H 2007 Synth. Commun. 372815

27. Ramsden Christopher A and Rose Helen L 1997 J. Chem. Soc. Perkin Trans. 12319 